Learning Outcomes While some migrant communities readily engage in programs that provide multiple benefits, the impact on reducing inequalities within drowning will be limited unless broader multi-strategic approaches are undertaken.

\section{B.004 REDUCING DROWNING MORTALITY AND MORBIDITY THROUGH SCHOOL AWARENESS PROGRAM IN RURAL BANGLADESH}

Saha Ashim Saha*, Dutta Notan Chandra, Naym Uddin, Aminur Rahman, Fazlur Rahman. Centre For Injury Prevention and Research Bangladesh (ciprb), Dhaka, Bangladesh

10.1136/injuryprev-2021-safety. 194

Context Drowning is a leading cause of death globally. Fatal drowning among children is more than adult. To reduce drowning morbidity and mortality among school aged children awareness program is implemented where increasing water safety knowledge among them.

Process Water related safety messages sessions were conducted in classrooms by a School Educator from grade I to VIII with support of Coordinator. He monitored the sessions and analyzed monitoring data. A total 266 schools were covered from 2018 to 2019 in three sub-districts of Barishal Division.

Analysis Coordinator has organized 97\% pretest amongst students. 45\% Boys \& 55\% Girls were participated in the pretest session. The Educator has showed water safety messages flipchart in 95\% sessions. About 95\% students were engaged in feedback session which was interactive. The Educator has provided hands-on training in 98\% times through the students on demonstration session. The approach of Educator was equal to the students during session delivery. At 95\% times, the session delivery speech was understandable. The School Educator operated the session functionally in $97 \%$ sessions and he wore with unique uniform in $98 \%$ times while conducting school session for awareness of the students.

Outcomes The interactive sessions were conducted for the students where briefing water safety messages of drowning prevention. The students have encouraged for disseminating the water safety information amongst the communities.

Learning Outcomes If the students work individually in local communities for disseminating the water safety information, it will play a pivotal role for increasing mass awareness of the whole community.

\section{B.005 ASSESSMENT OF EXISTING PASSIVE SURVEILLANCE SYSTEM FOR DROWNING PREVENTION IN COASTAL BANGLADESH}

Saha Ashim Saha*, Dutta Notan Chandra, Aminur Rahman, Fazlur Rahman. Centre For Injury Prevention and Research Bangladesh (ciprb), Dhaka, Bangladesh

\subsection{6/injuryprev-2021-safety. 195}

Background Some water bodies of Barishal become the cause of drowning point, which is a major killer where death occurs up to 19,500 each year. Among them, 14,500 are children (0-17 years). Barishal has the highest rate of drowning mortality, which is nine deaths per day.

Methods In spite of huge number of fatal drowning was public health threat, it often goes unregistered in government
MIS system. Passive drowning surveillance system is to develop a data generation system within government setting to obtain number of fatal drowning in the intervention sites.

Results Passive drowning surveillance system has slightly developed based on local government death registration system exist at the union level. The key findings of Union Council register book in Kolapara, Taltoli and Betagi areas, it has found only 17 drowning death case registered partially. The CIPRB staffs have collected 41 drowning death information's from the local communities during 2017 to 2019. The Union council Secretary \& Information officer does not usually record any death case on register book regularly. So unrecorded death notification has hampered on the track of actual drowning status in Barishal regions.

Conclusion Due to lack of fulfil effectiveness, drowning death information was received partially from the death register book of the Union councils. However, the community level information showed discrepancy in both number of deaths information.

Learning Outcomes The Government should have a mechanism about actual magnitude of the drowning death; there would be strengthen passive surveillance system to reduce drowning situation in Barishal areas.

\section{C - WHS, March 25, 2021}

\section{C.001 TOWARDS DECENT, SAFE WORK: LEARNINGS FROM WORK-RELATED FATAL INJURY IN NEW ZEALAND}

${ }^{1}$ Rebbecca Lilley*, 'Bronwen McNoe, 'Gabrielle Davie, 'Simon Horsburgh, ${ }^{2}$ Tim Driscoll. ${ }^{1}$ University of Otago, New Zealand, Dunedin, New Zealand; ${ }^{2}$ University of Sydney, Sydney, Australia

\subsection{6/injuryprev-2021-safety. 196}

Decent and safe work for all are key tennants of the Sustainable Development Goals. New Zealand's (NZ) workplace fatality record is high compared to similar OECD countries, with the reasons for its substandard performance unclear and limited by a lack of detailed data. This study aims to inform injury prevention efforts for NZ by: i) enumerating the work-related fatal injury burden; and ii) identifying high risk groups

Methods A work-related fatal injury dataset spanning the period 2005-2014 was created by: 1) identifying possible cases aged 0-84 years from mortality records using selected external cause of injury codes, 2) linking these to Coronial records and 3) reviewing and coding work-related cases. Work-related deaths were classified as workers, bystanders, commuters or students. Frequencies and rates per 100,000 workers were calculated.

Results of 7,730 injury fatalities reviewed, 1,924 (24\%) were work-related, of which 955 were workers. This corresponds to an overall rate of fatal injury of 4.8 (95\% CI 4.5, 5.1) per 100,000 workers. Rates of fatal injury were highest for indigenous Māori $(7.7,95 \%$ CI 6.6, 8.7), workers aged $>70$ years $(18.1,95 \% \mathrm{CI} 14.8,21.8)$ and males $(8.1,95 \% \mathrm{CI}$ 7.7, 8.5). The 'Agricultural, Forestry, Fisheries', and 'Transport, Postal, Warehouse' sectors both had a high burden of fatal injury.

Conclusions Work-related injury makes a substantial contribution to the overall burden of fatal injury. To deliver decent 
and safe work for all,work-related safety actions need to include a focus on males, older workers, and workers in the primary production and transport sectors.

\section{C.002 LABORATORY SAFETY STANDARDS AND THEIR IMPORTANT IN LAB SAFETY AND TRAINING}

Neale Jackson*. Lisa J Stevens and Associates, Newport, Australia

10.1136/injuryprev-2021-safety. 197

Every year, preventable laboratory accidents either kill or maim laboratory workers. Yet despite the plethora of legislation, regulations and Standards, these incidents continue to happen. One of the key methods of reducing laboratory based incidents is AS/NZS2243 Safety in Laboratories series and AS 2982 Laboratory Design and Construction. These standards are unique as there is no other in-depth and substantive laboratory standards in the world.

This paper, using case studies, will provide an overview of AS/NZS 2243 an AS/NZS 2982 how by adopting these laboratory safety standards, that laboratory based incidents can be prevented.

\section{C.003 BARRIERS OF SAFETY PRACTICE AND HEALTH-SEEKING BEHAVIOR AMONG FISHERMEN IN COASTAL BANGLADESH}

Notan Chandra Dutta*, Aklima Anwar Mitu, AKM Fazlur Rahman, Aminur Rahman. Centre for Injury Prevention and Research Bangladesh, Mohakhali, Dhaka, Bangladesh

\subsection{6/injuryprev-2021-safety. 198}

Background Over 37 million people are involved in fishing occupation worldwide, around $90 \%$ are from Asia. Bangladesh is a riverine country bordering with the Bay of Bengal where fishing is a vulnerable occupation as they exposed to water related risks and affected by disaster. There is limited information on drowning and its health consequences among fishermen. The objectives of the study were to explore the barriers of safety practices and identifying health-seeking behavior of the fishermen in coastal Bangladesh.

Methods A qualitative study was conducted between OctoberNovember 2016 deploying IDIs, FGDs with fishermen, lenders and boat owners along with fishing practices observations. Transcribed data were coded into NVIVO-11, then analyzed by thematic contents.

Results Fishermen mentioned they prioritized livelihoods over their safety. Instability in work and financial hardship contributed to risk-taking behavior of fishermen. They usually went for fishing in sea as forced by boat-owners or local lenders from whom taking loan for fishing-net. Many women engaged in fishing with their young children and faced drowning-risks because their traditional cloths restricted free-movement in water. Fishermen usually carried first-aid box in sea, but those were not sufficient. Most of the fishermen didn't have adequate knowledge on CPR, used traditional methods in case of any drowning-case.

Conclusion Fishing occupation is high exposure to drowning risks in the coastal region of Bangladesh.

Learning Outcomes Legislation on carrying life-saving equipment on fishing boats and training on resuscitation of post drowning during fishing in sea would be crucial intervention to reduce drowning among the fishermen.

\section{C.004 LABORATORY SIGNAGE, IS THERE A CLUTTER ISSUE?}

Maria Somodevilla Torres*. The University of Queesnland, Brisbane, Australia

10.1136/injuryprev-2021-safety. 199

Work areas such as research laboratories expose workers to a variety of hazards with different risk levels. Providing adequate safety in these environments is an extremely complicated exercise that can only be achieved with adequate training as well as effective visual signage. In work places like The Australian Institute of Bioengineering and Nanotechnology, where each area is subjected to stringent government regulations on top of the inherent risks posed by the existing chemicals and instrumentation, there is a risk of over-accumulation of signage with the net result of overloading the senses of users. My Masters' literature review research project identified a number of ideal features to facilitate noticeability, visibility and comprehension of signs and it is therefore crucial to abide by best practice. Signage at my institute was collected and classified according to published and revised criteria. The analysis highlighted issues with clutter display. Effective design and placement of signage needs to be undertaken using a multidisciplinary approach incorporating social psychology, communication studies and the visual creative sciences, as well as taking into consideration cultural differences among the intended audience.

\section{C.005 POST-PREVENTION CONTROL: MODERATING THE GROUND HANDLERS' FATIGUE AND SAFETY PERFORMANCE OUTCOMES}

Muhafiza Musa*. Universiti Teknologi Petronas, Bandar Seri Iskandar, Malaysia

10.1136/injuryprev-2021-safety.200

The aircraft ground handling is widely known as complex operations with adverse working conditions in the air transport industry. The significant growth of the industry require an extensive ground handling services to cater the demand from air traveller and cargo. The ground handling workers were overwhelmed by work and prolonged fatigue, thus leading to workplace accidents or near misses. The study aims to investigate the relationship between fatigue and safety performance outcomes of ground handling workers, and to examine whether the post-prevention control of accident/incident can change the magnitude of the relationship. A sample of 523 workers were drawn from four major ground handling companies operated at Malaysia's international airports to participate the survey. The results indicated that were significant relationship between physical and emotional exhaustion with accidents and near misses as well as working condition and near misses, but not with accidents. The results also revealed that post-prevention control only influenced the physical and emotional exhaustion with near misses, in contrast with accidents or relationships between working condition with accidents and near misses. The study 